\section{Sérgio Buarque de Holanda na USP}

Rodrigo Ruiz Sanches ${ }^{1}$

Resumo: O objetivo deste artigo é descrever e analisar a trajetória de Sérgio Buarque de Holanda na Universidade de São Paulo. Na USP, pôde dedicar-se inteiramente ao que mais gostava: pesquisar. Lá, formou um grupo de pesquisadores e mudou os rumos do ensino do curso de História que, à época, formava somente professores para o Ensino Fundamental e Médio. Idealizou e fundou, também, o Instituto de Estudos Brasileiros, órgão multidisciplinar responsável por importantes pesquisas que orbitam o tema Brasil. No IEB formou um amplo arquivo e uma importante biblioteca. Os 13 anos na USP se encerram num processo conturbado em 1969, quando pede sua aposentadoria em solidariedade aos outros professores aposentados compulsoriamente pelo Al-5.

Palavras-chave: Sérgio Buarque de Holanda, Universidade de São Paulo, Intelectual independente.

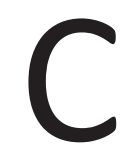

riada em 1934, a Universidade de São Paulo inicia-se pela Faculdade de Filosofia, Ciências e Letras concebida como centro de altos estudos e da cultura livre e desinteressada, um lugar de produção da cultura filosófica, científica, literária e artística. Tinha como objetivo, também, a formação das elites dirigentes de São Paulo e da nacionalidade. Além disso, foi definida, embora de maneira vaga, no projeto, a função social da universidade, qual seja, a de atender à variedade e necessidades dos grupos sociais (cf. CARDOSO, 1982). Para Pécaut (1990), a formação de uma "elite dirigente" implicava não só o respeito por uma hierarquia social, herdada ou adquirida, mas determinava também a teorização da política como competência: a arte de governar relaciona-se com o saber científico.

Dentre suas experiências acadêmicas, aquela mais intensa para Sérgio Buarque de Holanda foi, sem dúvida, na Universidade de São Paulo. Já consagrado como um dos mais importantes historiadores do Brasil, Sérgio Buarque de Holanda é convidado a ingressar como professor-substituto na Cadeira de História da Civilização Brasileira, em 1956. No entanto, seu contato com a USP vem desde 1949, quando participava de bancas de arguição de teses de doutorado, livre-docência e cátedra, nas áreas de História, Política e Economia.
Recebimento:

30.08.2010

Aprovado:

24.02.2011

1. Sociólogo, mestre e doutor em Sociologia pela Unesp/ Araraquara.

Docente da Faculdade Barretos-SP. Coordenador do Núcleo de Responsabilidade Social. e-mail: rodrigorsanches @yahoo.com.br 
2. Conforme Portaria da Faculdade de Filosofia, Ciências e Letras, da USP, de 11-12-56 (Proc. 11797/56, fl. 16)

3. Conforme Informação Reitoria da USP n. ${ }^{\circ}$ 2069/56, de 11-12-56 e DO de 8-12-56.

4. Conforme Proc. 11787/56, fl. 2.

5. Conforme D.O. de 2-10-56.

6. Conforme Proc. $11787 / 56$, fl. 5

7. N. 2638 , de 5-956 (Proc. 11787/56, fl. 6).
Em um debate sobre Sérgio Buarque de Holanda, Antonio Candido relata a seguinte história sobre seu ingresso na USP:

O professor de História da Civilização Brasileira na Faculdade de Filosofia da Universidade de São Paulo era Alfredo Ellis Júnior, que se afastou devido a graves problemas de saúde. Foi então que o nosso falecido amigo Lourival Gomes Machado, professor de Política, teve a idéia de chamar Sérgio, que foi contratado. Mas quando se tratou da efetivação, surgiu um impedimento legal: formado em Direito, Sérgio não podia fazer o concurso, porque a matéria não constava do seu currículo superior. Recorreu-se então ao seguinte: Sérgio se inscreveu no curso de mestrado da Escola de Sociologia e Política, na próxima matéria que ensinava, e cada semana um professor era convidado para dar aulas que ele ouvia junto com os estudantes. No fim apresentou um trabalho, recebeu o grau e pôde inscreverse no concurso da Faculdade de Filosofia. (CANDIDO, 1992, p. 86)

Lecionou na USP como Professor Catedrático Interino da Cadeira de História da Civilização Brasileira, a partir de 4 de dezembro de $1956^{2}$, quando o professor Alfredo Ellis sofreu um enfarto e, dolorosamente, aposentou-se ${ }^{3}$. Ocupou esse cargo até 1958, quando foi aberto concurso para a cátedra. Esse cargo foi oferecido a Sérgio Buarque de Holanda em 29 de agosto de 1956, por Eurípides Simões de Paula, que queria o início da atividade em $1^{\circ}$ de setembro ${ }^{4}$. No entanto, o historiador não pôde assumir tal cargo naquele momento, pois já ocupava um cargo público (Diretor do Museu Paulista) e não houve compatibilidade de horário, sendo o pedido do diretor da Faculdade de Filosofia, Ciências e Letras negado pelo Governador ${ }^{5}$. Mas, em carta de Eurípides Simões de Paula, endereçada a Sérgio Buarque de Holanda, o Diretor explica que o ofício encaminhado ao governador não especificou o horário, que seria da seguinte maneira: das $14 \mathrm{~h}$ às $17 \mathrm{~h}$, aulas e seminários a cargo do Assistente e, das $17 \mathrm{~h}$ às $19 \mathrm{~h}$, aulas a cargo do Dr. Sérgio Buarque de Holanda ${ }^{6}$. Parece-me, por meio da análise de algumas comunicações, que houve problemas de "acumulação de cargo", já que as duas funções que o historiador pretendia exercer, Diretor do Museu Paulista e Professor Interino, são públicas, devendo ser analisada pela Comissão de Acumulações. Em novo ofício ${ }^{7}$, o Diretor da FFCL encaminha ao Presidente da Comissão de Acumulações o novo horário do professor Sérgio Buarque de Holanda, a saber: segunda, das $15 \mathrm{~h}$ às $16 \mathrm{~h}$, no $4^{\circ}$ ano, curso regular, das $16 \mathrm{~h}$ às $17 \mathrm{~h}$, no $4^{\circ}$ ano, Especialização - Orientação/Trabalhos-Seminários; terça, das $16 \mathrm{~h}$ às $19 \mathrm{~h}$, no $2^{\circ}$ ano diurno, duas aulas e um Seminário, das $19 \mathrm{~h}$ às $20 \mathrm{~h} 30$, no $2^{\circ}$ ano noturno, duas aulas e um Seminário; sexta, das $14 \mathrm{~h}$ às $17 \mathrm{~h}, 3^{\circ}$ diurno, duas aulas e um Seminário, $20 \mathrm{~h}$ às $23 \mathrm{~h}$, no $3^{\circ}$ noturno, duas aulas e um Seminário. O Diretor faz lembrar que o horário do interessado como Diretor do Museu Paulista é pela manhã. 
O parecer ${ }^{8}$ final afirma que o

Cargo de Diretor do Museu Paulista é de natureza técnico-científica, não podendo ser ocupado por pessoa se não de conhecimentos especializados, entre outros, de História. O outro cargo é de Magistério, sendo evidente a correlação de matérias. Todavia, a acumulação não foi admitida por incompatibilidade de horário, visto que, nas sextas-feiras, o interessado deverá estar às 14 horas no Museu e na Faculdade.

Como foi esclarecido que o horário das sextas-feiras estava errado, a Comissão de Acumulação de Cargos decide pela legalidade da acumulação. Como o cargo de interino é de tempo integral ${ }^{9}$, Sérgio Buarque de Holanda teve de pedir afastamentos ${ }^{10}$ do Museu Paulista no tempo em que ministrou aquela cadeira interinamente.

Em 13 de setembro de 1958, Sérgio Buarque de Holanda comparece ${ }^{11}$ à Secretaria da Faculdade de Filosofia, Ciências e Letras da USP com um requerimento solicitando inscrição ao concurso para provimento efetivo da Cadeira de História da Civilização Brasileira ${ }^{12}$. Com o requerimento, ele apresentou os documentos exigidos pelo regulamento do concurso, além da tese intitulada "Visão do Paraíso - Os motivos edênicos do descobrimento do Brasil", e comprovantes de sua atividade profissional ${ }^{13}$ e cultural, cerca de 43 , além de 16 cópias de trabalhos impressos.

Às $13 \mathrm{~h}$ do dia 10 de novembro de 1958, a Comissão Julgadora, composta pelos Professores Eurípides Simões de Paula e Eduardo D'Oliveira França, representando a Congregação da Faculdade, Afonso Arinos de Melo Franco, José Wanderley de Araújo Pinto e Hélio Viana, escolhido pelo conselho Técnico-Administrativo e pelo Senhor Diretor da Faculdade, Prof. Dr. Paulo Sawaya, dão início ao concurso. Há relatos do constrangimento dos avaliadores em exigir experiência docente e em pesquisa a um homem do quilate de Sérgio Buarque de Holanda, mas era assim que rezavam as normas na universidade naquele tempo. Soares Amora afirma, na época, estar inconformado com a estrutura da universidade, "exigir de homens da estatura intelectual e do saber de Sérgio Buarque de Holanda um concurso de provas"14.

A primeira etapa foi a prova escrita. Foi sorteado o ponto de n. 13, "A conquista da paz interna e a conciliação política", de um total de 20 pontos. Às 15h, iniciase a prova escrita, encerrando-se às 20h50. A prova foi escrita à mão e contém 26 páginas ${ }^{15}$.

Às $13 \mathrm{~h}$ do dia 12 de novembro de 1958, no salão nobre da Faculdade, realizouse, em sessão pública e solene, a defesa de tese apresentada pelo candidato, intitulada "Visão do Paraíso". Depois se procedeu à arguição dos membros
8. Comissão de Acumulação de Cargos, processo GG-4316/56, parecer 498 , de $19-10$ 56, DO de 28-10-56 (Proc. 11787/56, fls.8-9).

9. Conforme Parecer n. ${ }^{\circ} 156 / 56$ da Comissão Permanente de Tempo Integral, de 30-11-56 (Proc. 11787/56, fl. 14).

10. Conforme Ofício 2575, de 13-09-57 (Proc. 11787/56, fl. 21).

11. Em entrevista, Sérgio revela que se ele não prestasse o concurso de Cátedra, seria demitido. (HOLANDA, 2004, p. 5)

12. Processo RUSP 757/58.

13. Para poder inscrever-se, Sérgio teve de comprovar experiência docente. Foi então convidado, no dia 13 de dezembro de 1955, para ministrar aulas na FFCL de Sorocaba, na cadeira de História do Brasil. Sua nomeação, feita por Dr. Dom Beda Cruse, diretor desta Faculdade, data de 15 de março de 1956.

14. Universidade de São Paulo. Administração. Processo $757 / 58$. Faculdade de Filosofia, Ciências e Letras, Curriculum Vitae, de 15 set 1958.

15. A cópia dessa prova está no Centro de Apoio à Pesquisa em Histórica "Sérgio Buarque de Holanda", da USP, 
na pasta 10 da hemeroteca. Trechos foram publicados na Folha de S. Paulo, de 19-04-1992, cad. 5, p. 8.

16. Conforme Ata do Concurso e Relatório da Comissão Julgadora (Proc. 17839/58, fls. 3-4).

17. Conforme Relatório da Comissão Julgadora (Proc. 17839/58, fls. 3-4).

18. Conforme Informação n. ${ }^{\circ} 1869 / 58$, do Proc. 17839/58, fl. 6 .

19. Conforme Proc. 17839/58, fl. 7. da banca.

Às 19 h30 do dia 13 de novembro de 1958, na sala do Conselho Técnico e Administrativo da Faculdade de Filosofia, Ciências e Letras, realizou-se o sorteio da prova didática, com 20 pontos. Foi sorteado o ponto número 19, "Técnicas rurais e sua evolução no Brasil: indígenas e contribuição adventícia". Às 19 h30 do dia 14 de novembro de 1958, no salão nobre da Faculdade de Ciências e Letras, localizada na Rua Maria Antonia, 294, foi realizada a prova didática e, logo após, a leitura da prova escrita. Em seguida, passou-se à verificação das notas atribuídas às diversas provas do concurso, conforme transcritas abaixo ${ }^{16}$ :

\begin{tabular}{|l|c|c|c|c|c|}
\hline \multicolumn{1}{|c|}{ Avaliadores } & Títulos & $\begin{array}{c}\text { Prova } \\
\text { Escrita }\end{array}$ & $\begin{array}{c}\text { Defesa } \\
\text { de tese }\end{array}$ & $\begin{array}{c}\text { Prova } \\
\text { didática }\end{array}$ & Média \\
\hline Prof. Afonso Arinos de Melo Franco & 10 & 9,0 & 10 & 9,0 & 9,5 \\
\hline Prof. Hélio Viana & 10 & 9,0 & 10 & 9,5 & 9,5 \\
\hline Prof. Wanderley Pinho & 10 & 10 & 10 & 10 & 10 \\
\hline Prof. Eduardo D'Oliveira França & 9,5 & 9,5 & 10 & 10 & 10 \\
\hline Prof. Euripedes Simões de Paula & 10 & 10 & 10 & 10 & 10 \\
\hline
\end{tabular}

Houve um examinador, diz Linhares (1987) sem mencionar o nome, que criticou a feitura da tese, atribuindo-Ihe, antes, a qualificação de ensaio, "por não esgotar a respectiva matéria" e na interpretação do mito e sua função nos móveis de expansão marítimo-mercantil portuguesa.

No dia 14 de novembro de 1958, foi decretado o seguinte resultado:

A vista destes resultados foi o candidato aprovado com distinção e a comissão julgadora indica-o para a regência efetiva, em regime de tempo integral, da Cadeira de História da Civilização Brasileira, da Faculdade de Filosofia, Ciências e Letras da Universidade de São Paulo ${ }^{17}$.

Sua nomeação foi assinada por Maria José Villaça Vessoni, reitora da USP, no dia 3 de dezembro de $1958^{18}$, e pelo então Governador Jânio Quadros, em 18 de dezembro de $1958^{19}$, e consta no Diário Oficial, fls. 2 do decreto 18 , de 19 de dezembro de 1958, e retificado no Diário Oficial de 20 de dezembro de 1958.

O ingresso na universidade, exatamente nesse período, coincidiu com o momento de maturidade intelectual do historiador e o momento de grande prestígio da universidade pública. Os anos 60 foram, para Marcelo Ridenti, a era do "romantismo revolucionário", período de grandes mudanças no campo cultural, sexual, costumes, político, juntamente com a emergência da mídia. Para ele, as

Universidades, jornais, rádios, televisões, agências de publicidade, empresas públicas e privadas tendem a fornecer ótimas oportunidades a profissionais qualificados, dentre os quais se destacavam os que consideravam 
de esquerda, expoentes da cultura viva do momento imediatamente anterior. (RIDENTI, 2003, p. 204)

Assim, para Sérgio Buarque de Holanda, a USP seria a possibilidade de realizar um trabalho acadêmico que conciliasse as coisas mais importantes para um profissional: pesquisa e orientação.

Na Cadeira XXVIII, História da Civilização Brasileira, Sérgio Buarque de Holanda pôde reorganizar todo conteúdo programático e a bibliografia disponível. No Anuário de $1959^{20}$, consta como Professor-Assistente a Dra. Myriam Ellis e Auxiliar de Ensino a Lic. Maria Thereza Schorer Petrone. O programa está ordenado por ano, sendo que o 2ㅇ ano teve como assunto "A mineração no Brasil Colonial", o 3ㅇano "Da conciliação à Guerra do Paraguai", História do Brasil para o 4ํ ano, com o tema "Monções" e o curso de História do Brasil para o curso de Geografia, a cargo do Lic. Odilon Nogueira de Mattos. Ao que parece, esse plano, com os respectivos tópicos, durou os anos de 1960 e 1961. Em 1962, ocorrem algumas mudanças. O tema para o 2으 ano é "Dos fins do Período Colonial à fundação do Império". O 3o ano é "Da queda do Gabinete Zacarias de Góes ao advento da República". "O Café no Brasil Colonial" é o tema do 40 ano e a disciplina História do Brasil para o Curso de Geografia permanece igual. Esse programa permaneceu até 1964 . A partir de 1965, não consta mais o nome do Catedrático, do Professor-Assistente e do Auxiliar de Ensino. Também não há divisão por série, aparecendo somente os temas "História Colonial - Expansão Geográfica do Brasil Colonial" e "História do Império - O Primeiro Reinado e a Desagregação da Herança Colonial". Esse programa permanece até 1967. Em 1968 e 1969, novamente há alterações no programa: Tema I: “O Brasil - Colônia num mundo em transformação - De Pombal ao Retorno de D. João VI" e Tema II: "Brasil Independente - A ordem conservadora do Segundo Reinado".

No entanto, os Diários de Classe consultados constam que Sérgio Buarque de Holanda lecionou as seguintes disciplinas: História da Civilização Brasileira 2 (Colônia), História da Civilização Brasileira 3 (Império e República), História do Brasil, História do Brasil (Geografia). Também é possível verificar que tais cursos foram ministrados tanto para as turmas do diurno quanto para as turmas do noturno.

No tempo em que era catedrático da USP, Sérgio Buarque de Holanda participou de diversos eventos científicos. Parte fundamental e obrigatória da carreira acadêmica, tais eventos, tanto no Brasil como no estrangeiro, foram relacionados a seguir com o intuito de dar uma dimensão da produção científica do historiador.

Em 1959, participou ainda do 2ํ e 3ํ Colóquios Luso-Brasileiros, reunidos em Salvador. Participou do Primeiro Simpósio de Professores de História do Ensino Superior, ocorrido na Faculdade de Filosofia, Ciências e Letras da cidade
20. Consultado na "Área do Aluno" no Setor Administrativo da FFLCH, da USP. 
de Marília, entre os dias 15 e 20 de outubro de 1961. Durante esse encontro, foi fundada a Associação de Professores Universitários de História - APUH.

A convite da Faculdad de Filosofia y Educacion da Universidad del Chile e de seu Centro de Investigações de História Americana, em 1963, ministrou um curso (de seis meses) e organizou seminários de História do Brasil, juntamente com os Professores Ruggiero Romano (História da América Espanhola) e Max Savelle (História dos Estados Unidos). Editou-se um volume desse evento pela mesma universidade, sob o título: Tres lecciones inaugurales - Buarque, Romano, Savelle (Santiago do Chile, 1963).

Em 1965, viaja aos Estados Unidos, agora como professor convidado nas Universidades de Indiana (Bloomington) e de New York State (Stone Brook), tendo, além disso, organizado seminários e participado de outras atividades didáticas na Universidade de Yale, como a participação numa banca de doutoramento. Em Princeton, encontrou-se com os professores Stanley Stein e Kenneth Maxwell. Participou do VI Colóquio de Estudos Luso-Brasileiros em Harvard e Colúmbia. Pronunciou uma palestra no Queen's College, em Nova York. Fez conferências e participou de seminários na Universidade de Colúmbia, em 1965, na Universidade de Yale, convidado por Richard Morse e David Davidson, Califórnia (Los Angeles), Harvard, ambas em 1966. Em 1967, terminou o curso em Stone Brook e proferiu uma palestra na Universidade de Princeton.

Convidado pela UNESCO para integrar o Comitê de Estudos das Culturas LatinoAmericanas, participou das reuniões do referido comitê, efetuadas em Lima, em novembro e dezembro de 1967, e em San José de Costa Rica, em agosto de 1968, e na Ciudade del México, em 1974. Foi ao Paraguai, em 1968, a fim de pesquisar documentos relacionados com o Brasil. Colaborou com o capítulo "Die Geschite Eines tablen Kontinentes" (A História de Meio Continente), no livro "Brasilien" da Atlantis Verlag A. G. - Zurique.

Em 1967, viajou a Cuiabá para realizar pesquisas no Arquivo. Ainda em 1967, proferiu uma conferência na Escola Superior de Guerra sob o título "Elementos básicos da nacionalidade - o homem". Viajou várias vezes, a partir de 1968, para a Bahia, num intercâmbio com as duas universidades estaduais, a fim de participar de um curso sobre o Recôncavo.

Orientou, em 1962, as primeiras teses de mestrado de toda a universidade. Estimulou o desenvolvimento de pesquisa sobre os mais diversos temas dos períodos colonial, imperial e republicano da História brasileira, do que resultaram teses acadêmicas importantes, como, por exemplo, O fardo do homem branco, Maria Odila Leite da Silva Dias; A Revolução de 1930, de Boris Fausto; A lavoura canavieira em São Paulo, de Maria Theresa Schorer Petrone; Ibicaba, uma 
experiência pioneira, de José Sebastião Witter; Escravidão negra em São Paulo, de Suely Robles Reis de Queiroz (CALDEIRA, 2005). A Faculdade de Filosofia mantinha intercâmbio com a Sorbonne e com as universidades da Inglaterra e as dos Estados Unidos, além de manter contato com os pioneiros brasilianistas, como Stanley Stein, Richard Morse e, em Londres, Charles Boxer (DIAS, 1994, p. 271). Em 1964, deu um curso de História do Brasil na Universidade de Brasília, cujo reitor era Zeferino Vaz.

Na Universidade de São Paulo, Sérgio Buarque de Holanda pôde, também, conduzir uma série de mudanças nos rumos da docência e da pesquisa na universidade. Preocupado com a formação de pesquisadores, ele mudou os objetivos do curso de História, que somente preparava os alunos para o exercício do magistério. Respeitando essa nobre formação, ele procurou também formar pesquisadores, ampliando, assim, o campo de atuação desses jovens formandos. Por mais de uma vez, e sempre por eleição, exerceu a chefia do Departamento de História da USP, embora tenhamos a impressão de que Sérgio não gostava muito de exercer cargos de chefia.

Quando perguntado o que ele considera ter sido sua maior satisfação como historiador, ele disse: "Minha satisfação foi ter conseguido formar um grupo de verdadeiros historiadores. Eu formei um grupo, mas cada um seguiu seu próprio caminho" (GRAHAM, 1987, p. 105). Essa impressão é comprovada por depoimentos de seus ex-orientandos, como Maria Odila Leite da Silva Dias e José Francisco Witter. Uma das mais importantes funções realizadas por Sérgio Buarque de Holanda na USP foi, sem dúvida, a orientação de trabalhos de pesquisa, como monografias, dissertações e teses. Foram dezenas assinadas por ele e um número grande de co-orientações que não aparece oficialmente, somente sendo encontrado nos agradecimentos. A orientação de pesquisas parece ter sido uma das funções que mais lhe agradava, exercendo essa função mesmo depois de sua aposentadoria. Witter (2002b) confirma o seu gosto por esse trabalho, pois eram cuidadosamente lidos e corrigidos pelo orientador Sérgio.

Mas Sérgio Buarque de Holanda apontava alguns problemas burocráticos que dificultavam a orientação. Por exemplo, aqueles que eram convidados para serem Professores-Assistentes, destinavam-se, principalmente, a ministrar aulas, tendo suas pesquisas reduzidas no âmbito das dissertações e teses. Outro problema apontado por ele era a dificuldade de se trabalhar com arquivos, pois muitos destes se encontravam distantes de São Paulo, desprendendo muito tempo e dinheiro para ir até eles. Dessa forma, Sérgio Buarque de Holanda pretendia valorizar a pesquisa entre os assistentes, deixando-os à vontade para a escolha do tema, mas mantendo o rigor científico e documental que tal empreitada exigia.

Além da atividade como orientador, Sérgio Buarque de Holanda exerceu, na USP, 
a função de docente. É interessante observar as opiniões de Witter sobre o professor Sérgio Buarque de Holanda:

Nada tinha do tradicional professor, de aulas bem preparadas e organizadas em fichas, seguindo os métodos pedagógicos vigentes na época. Era o oposto de tudo quanto tinha aprendido na minha formação de professor primário. Isso começou por me encantar, embora, em certos momentos, sentisse muito a ausência de um método bem estruturado (...) ele divagava, divagava sempre... Buscava cuidadosamente a melhor palavra para criar a melhor imagem para o que deseja transmitir (...) Acompanhar Sérgio nem sempre era fácil. Perdia-se, e quantas vezes, o 'fio da meada' e para reencontrá-lo era necessário o esforço despendido nas 'loucas noites universitárias', quando os grupos de estudo, espontaneamente formados, procuravam nos apontamentos de sala de aula as linhas mestras do pensamento do professor e a partir delas buscavam na bibliografia sempre correspondente por ele citada aquilo que faltava. (WITTER, 1988, p. 58)

Sérgio Buarque de Holanda diferencia-se dos demais professores, pois tem uma atuação didática muito peculiar. Os ex-alunos não declaram que era um mau professor, mas deixam a entender o método um pouco confuso de suas explanações.

Sérgio era, no entanto, sempre um professor... Dentro da sala de aula, nos corredores da Maria Antonia, nas escadarias do prédio da Velha Reitoria da USP ou no moderno edifício da Geografia e História - subindo ou descendo a rampa - ele estava sempre atendendo alguém, ouvindo, ironizando, mas sempre ensinando. Foi para mim, um MESTRE. Também não deixava de sê-lo naquela saudosa sala de estar da Rua Buri, onde, sentado no seu sofá predileto, passava horas e horas a nos falar sobre seus temas preferidos de História, abrindo caminhos para nossas pesquisas. (WITTER, 1988, p. 58)

21. Witter (2002b). Witter, em outro momento ${ }^{21}$, reforça essa ideia da atenção dada pelo professor Sérgio para com os alunos e, principalmente, orientandos. Witter foi professor-assistente e dizia da liberdade dada por Sérgio para a realização de suas pesquisas. Dizia ele que Sérgio Buarque de Holanda não era paternalista, pelo contrário, apenas indicava caminhos. Para ser professor, diz Sérgio Buarque de Holanda, citado por Witter, "não é necessário ser sisudo, triste ou amargurado. E bom professor tem que ser alegre, cantar, rir, e ironizar com a sabedoria dos que amadurecem sem envelhecer". Nunca foi o "dono da verdade", diz Witter, pois sempre mostrava o quanto é importante que se duvide, que se questione, que se privilegie o benefício da dúvida... Não era "o Catedrático", mas, sim, o coordenador de estudos de História do Brasil, com o poder autêntico dos 
que lideram, porque conquistava e não se impunha por sua posição hierárquica. Era verdadeiramente um defensor da liberdade.

Mesmo assim, diz Witter, ele nunca foi um professor organizado, nada disso, seguidor do que determinava a didática. Witter afirma, ainda, que Sérgio Buarque de Holanda era um homem rigoroso, mas sem nunca ser ditador ou autoritário: "Ele era um catedrático por excelência". Witter, nesse mesmo texto, acredita que a extinção da cátedra, em 1968, talvez tenha sido um erro, mesmo exercida muitas vezes de forma equivocada ou mesmo autoritária. Para Witter, a atuação como catedrático tornava-o uma espécie de orientador ou mesmo de formador, um scholar, e os seus assistentes eram pessoas que iam aprendendo e, portanto, formavam uma equipe com alguém superior e o catedrático criava uma escola, uma linha de pesquisa.

Como catedrático e orientador, os relatos são sempre positivos. Witter (2002b) diz que o historiador sabia distribuir tarefas. Fazia isso no começo de cada ano e, no final, indicava uma bibliografia para ser lida pelos assistentes. Sérgio fazia reuniões semanais para averiguar as leituras e como andavam os cursos ministrados pelos assistentes.

Witter (1998) diz que havia na Faculdade de Filosofia, Ciências e Letras, da USP, cursos de pós-graduação que davam certificados de conclusão, qualificando os que o faziam com um título universitário. Sérgio Buarque de Holanda foi o único que, antes de as regulamentações oficiais exigirem, somente assinava esse diploma depois de os estudantes escreverem uma monografia de mestrado. Outro fato, lembrado por Witter, é a exigência, por parte de seus assistentes, da monografia de mestrado antes de se candidatarem para o doutorado. Para o Dr. Sérgio, continua Witter, o mestrado era uma etapa importante da formação acadêmica de cada um que pretendia fazer carreira na USP. Sérgio Buarque de Holanda via no mestrado a iniciação na difícil tarefa de escrever. Escolhido o tema e a pesquisa feita era o momento de amadurecimento, por meio da narrativa bem-feita daquilo que foi pesquisado. Sérgio Buarque de Holanda exigia de seus orientandos e assistentes muito cuidado na escrita e não aceitava descuido ou desatenção, como vimos no capítulo anterior.

Essa legislação sobre a pós-graduação no Brasil, na verdade, era ambígua até a década de 1960, como aponta Oliveira (1995). Em 196122, foi promulgada a Lei de Diretrizes e Bases da Educação Nacional (LDBEN) 4.024/61, onde surge pela primeira vez a expressão "pós-graduação", em seu artigo 69. No entanto, a imprecisão e indefinição do termo ainda persistem. Essa confusão durou até 1965, quando o Conselho Federal de Educação (CFE), por meio do Parecer 977/65, de autoria de Newton Sucupira, define a pós-graduação em dois tipos: stricto sensu (mestrado e doutorado) e lato sensu (especialização e aperfeiçoamento).
22. Na FFCL, da USP, entre 1945 e 1965, foram defendidas 41 teses (entre livre-docência, mestrado e doutorado). Entre 1976 e 1984, foram 971 teses de mestrado e 141 de doutorado (MICELI, 1989). 
Após o golpe de 1964, a política educacional dos militares enfatiza a formação de recursos humanos em nível técnico-profissional para atender às exigências do mercado. "O Estado passou a privilegiar os princípios de eficiência e produtividade do sistema educacional, nos moldes da visão empresarial tecnocrática" (OLIVEIRA, 1995, p. 59). Em 1968, o Decreto 62.937 constituiu o grupo de trabalho para a Reforma Universitária (GTRU), que desembocou na Lei 5.540, referente à Reforma Universitária. Para Oliveira (1995), fica evidente que essa Lei adotou a ideia de pós-graduação contida no Parecer 977/65. Mas uma política séria e única para a pós-graduação só veio após a criação do Conselho Nacional de Pós-Graduação, em 1974, e posteriormente a execução do I Plano Nacional de Pós-Graduação que vigorou no período de 1975-1979, com atuação importante da Capes.

Segundo Witter (1998, p. 27),

Sérgio dizia temer pela burocratização excessiva dos cursos e da realização das teses. Ele achava que o trabalho de pesquisa e elaboração de uma tese precisava de tempo. Um tempo interior de cada um. Esse tempo não podia ser administrado por outra pessoa que não fosse aquela envolvida no seu fazer.

O resultado de tudo isso nós podemos ver no legado deixado por ele no curso de História e no sucesso profissional obtido por quase todos os seus assistentes e orientandos. Entre eles constam: Myriam Ellis, Nícia Vilela Luz, Maria Teresa S. Petrone, Odilon Nogueira de Matos, Maria Odila L. S. Dias, Suely Robles Reis de Queirós, Laima Mesgravis, Maria de Lourdes Gianotti. Essas pessoas formam a "rede de relações" pela qual Sérgio transitava.

23. Queiroz (2005). Em depoimento ${ }^{23}$, Suely Robles Reis de Queiroz, ex-aluna, relata que Sérgio Buarque de Holanda era intransigente quanto à competência, pois não cedia a divergências políticas ou injunções mesquinhas de natureza pessoal ao selecionar os melhores profissionais que colaborariam com ele em algum projeto. Daí, Queiroz revela que, com ele, não havia o que nos meios intelectuais se convencionou chamar de "igrejinha".

\section{Instituto de Estudos Brasileiros (IEB)}

24. Um estudo sobre o IEB foi elaborado por Caldeira (2000).

25. A íntegra dessa carta pode ser lida em Holanda (1987, p. 80).
Um capítulo à parte em sua vida acadêmica na USP foi a idealização e a criação do Instituto de Estudos Brasileiros, o IEB ${ }^{24}$, onde foi presidente de 1962 a 1964. A proposta, presente na carta datada de 5 de outubro de $1962^{25}$ e destinada ao Diretor em exercício da FFLCH, da USP, prof. Dr. Cândido Lima da Silva Dias, era a 
de instalação de um Instituto e não de um Centro, porque este último, na estrutura da Faculdade, restringia-se ao âmbito de um Departamento específico, estando sujeito, portanto, às restrições próprias de uma disciplina, ao passo que o Instituto era dotado de um status igual ao de uma Faculdade, podendo agregar disciplinas diversas, contar com a colaboração de outras Unidades da Universidade, constituir unidade orçamentária, possuir seus próprios professores e funcionários, enfim, dispor de autonomia razoavelmente ampla. (CALDEIRA, 2000, p. 32)

Sérgio Buarque de Holanda viu um grave problema na formação acadêmica dos jovens historiadores formados na USP: a exclusiva preparação para o magistério. Não que ele considerasse esse trabalho menor, pelo contrário, mas acreditava que a formação deveria ser completada com a preparação para a pesquisa científica, levando o estudante ao aprendizado da utilização dos arquivos e dos documentos históricos, imprescindíveis para a formação do historiador. Como essa formação completa transbordava os limites da Cadeira de História Geral da Civilização Brasileira, bem como de todo o curso de História, Sérgio Buarque de Holanda propôs a criação de um Instituto que abarcasse essa disciplina e outras que pudessem contribuir de modo direto para um melhor conhecimento do Brasil nos seus diferentes aspectos. Essas disciplinas seriam: Geografia do Brasil, Literatura Brasileira, Antropologia, Política, Sociologia, Introdução aos Estudos Históricos e Paleografia, ou outras que se inserissem nesse contexto (CALDEIRA, 2000).

Veem-se nessa justificativa dois traços importantes do acadêmico: a preocupação com a formação ampla dos universitários e o entendimento completo do Brasil, caracterizado pela visão holística e sem preconceitos, acreditando que somente por meio da interdisciplinaridade seríamos capazes de compreender melhor nosso País.

Desde sua criação, o IEB possuía dois setores: setor de pesquisa e setor cultural. O setor de pesquisa teve como princípio relacionar diversos campos do saber, formando uma interdisciplinaridade com um objetivo comum: estudar o Brasil em sua totalidade. O setor cultural do IEB deve promover ou organizar cursos, conferências, sessões de debate, intercâmbio cultural, concursos e exposições. Daí o caráter amplo do instituto que, ainda hoje, é um importante centro de referência nos estudos sobre o Brasil.

Segundo o Regimento Interno ${ }^{26}$, são finalidades do IEB:

1) associar cadeiras e disciplinas relacionadas com os estudos brasileiros;

2) planejar e realizar, com investigadores de seu quadro e das várias 
cadeiras e disciplinas, pesquisas próprias, oferecendo condições para a sua efetivação e divulgação;

3) incentivar a participação de alunos de um curso nos trabalhos de cadeiras de outros, assegurando a convivência entre professores, alunos e investigadores estranhos ao quadro da universidade;

4) encaminhar alunos e ex-alunos no levantamento da documentação, em especial em bibliotecas e arquivos nacionais e estrangeiros, orientando-os em sua utilização;

5) realizar cursos ou seminários de natureza especial e expedir os respectivos certificados.

Um dos objetivos do IEB era reunir uma série de documentos históricos com a finalidade de criar um acervo e disponibilizá-lo aos pesquisadores que, de outra maneira, não teriam acesso a fontes importantes. É por isso que o instituto adquiriu valiosa coleção de obras raras sobre o Brasil, pertencentes às coleções particulares de F. de J. Almeida Prado, de Mário de Andrade, de Fernando de Azevedo, entre outros. Sérgio Buarque de Holanda sempre demonstrou que os alunos de história da USP deveriam, além da formação docente, obter uma sólida formação em pesquisa. Para isso, era necessário dispor de um lugar onde os alunos pudessem entrar em contato com fontes sem precisar deslocar-se para arquivos, muitas vezes distantes. Esse lugar seria o IEB.

Em seu Regimento Interno, de 10 de maio de 1965, o IEB previa: cursos de pósgraduação com duração de dois anos e um currículo que misturasse ciências humanas e literatura; cursos de seis meses, mais intensivo, para grupos de estudantes estrangeiros; cursos de três meses para pessoas encarregadas de tarefa no estrangeiro (leitores, jovens professores, bolsistas, etc.); orientação de pósdoutorado para estrangeiros.

José Sebastião Witter (2002), ex-presidente do IEB, afirma que o IEB é hoje aquilo que Sérgio Buarque de Holanda plantou. A grande força do IEB são a biblioteca

27. Siarq/Unicamp.

28. Nessa entrevista transparece certo ceticismo quanto à situação atual e até um certo pessimismo de Sérgio Buarque de Holanda pelos rumos que estava tomando a política educacional do regime militar (Folhetim, 26-061977, consultado em Siarq/Unicamp e o arquivo, em grande parte formada pelo professor Sérgio. Em carta datada de 15 de janeiro de $1963^{27}$, endereçada ao então Governador de São Paulo, Carlos Alberto A. de Carvalho Pinto, Francisco Matarazzo Sobrinho, dono da Metalúrgica Matarazzo S/A, indica a aquisição, pelo IEB, de cerca de 800 documentos originais e manuscritos referentes à história de São Paulo, pertencentes ao Arquivo de Souza Botelho Morão e que se encontravam à época em poder do Conde de Mongualde. Mesmo as outras coleções adquiridas posteriormente, como a de Caio Prado Jr., diz Witter, são do estilo que ele gostaria que estivesse lá.

Numa entrevista dada em $1977^{28}$, Sérgio Buarque de Holanda afirma que queriam acabar com o IEB, pois "o estatuto apresentava falhas". Nessa entrevista, já bastante pessimista, Sérgio Buarque de Holanda desabafa: "Eu quero morrer 
antes que o Brasil acabe". Acostumado ao frequente diálogo com pesquisadores de outras áreas, principalmente na Escola Livre de Sociologia e Política, Sérgio Buarque de Holanda sentiu a rigidez do regime de cátedras da USP que dificultava esse diálogo. No entanto, essa rigidez não atrapalhou sua independência, pois pôde realizar seu trabalho com qualidade e profissionalismo.

Esse diálogo com seus pares foi possível, de forma plena, quando coordenou a Coleção História Geral da Civilização Brasileira. Pôde manter contato com especialistas de diferentes matérias no estudo de temas brasileiros, o que o levou a observar

(...) que os estudos multidisciplinares sobre a história da civilização brasileira deveriam ser realizados continuamente, não podendo ficar restritos a uma única obra coletiva eventual. Portanto, de acordo com ele, fazia-se necessário criar uma instituição que possibilitasse o desenvolvimento permanente daqueles estudos na USP, e essa instituição era o IEB. (CALDEIRA, 2000, p. 34)

Além da criação do IEB, Sérgio Buarque de Holanda foi presidente das comissões organizadoras do Instituto de Pré-História, do Museu de Arte e Arqueologia da USP, do Museu de Arte Moderna e da Comissão de Bibliotecas, criados igualmente durante a gestão de Ulhoa Cintra. Dessa forma, pôde contribuir para a ampliação da pesquisa e do ensino no âmbito da Universidade de São Paulo, características até hoje indeléveis dessa instituição.

\section{A aposentadoria na USP}

Após o golpe de 1964, mas principalmente após a instauração do Al-5, a vida universitária passou por mudanças que transferiram os fóruns de discussão então existentes, de caráter democrático, para a esfera do poder Executivo, de caráter centralizador (CARDOSO, 2001). Com isso, o que se viu foi o desmonte de todo aparato universitário e da educação pública de um modo geral:

O confronto com o regime militar, no pós-68, consegue uma grande unanimidade nas esquerdas, na universidade, contra as cassações e prisões, contra a presença de representantes dos órgãos de segurança nas reitorias interferindo nas contratações dos professores, contra o modelo de exclusão cultural construído a partir do Al-5. Unanimidade na denúncia do abandono do ensino público pelo regime militar e a conseqüente implantação do modelo de privatização da universidade brasileira, com o rebaixamento do nível de ensino provocado por esta política; na denúncia da limitação de despesas com as universidades públicas e com a educação 
29. Universidade de São Paulo. Departamento Pessoal da Reitoria. Setor: Assentamentos. Matrícula: 2.471. Registro Funcional do Prof. Dr. Sérgio Buarque de Holanda.

30. Folhetim, 26 de junho de 1977 (Siarq/Unicamp).

31. Idem.
32. Conforme Ata da Reunião (FFLCH/ USP). pública de um modo geral; na denúncia da política dos governos militares de ênfase na prestação de serviços pelas universidades às empresas privadas e públicas, com o surgimento das fundações nas universidades estaduais e federais. (CARDOSO, 2001, p. 42)

Esses fatos provocaram indignação em todo meio universitário. Sérgio Buarque de Holanda é de supor pela coerência de suas ideias e pelas declarações sobre esses episódios, também se decepcionou com os rumos que estava tomando a universidade. Em solidariedade com os colegas aposentados discricionariamente pelo regime militar (cerca de 40) pelo Al-5, pede sua aposentadoria, encaminhada ao então Reitor, Alfredo Buzaid, em 30 de abril de 1969. Sobre esse episódio, declarou: "Tinha tempo de serviço, não perdia nada monetariamente... Mas achei que era meu dever"29. Em outro momento, Holanda reitera: "Em protesto e solidariedade. Agora, eu não acho que foi heroísmo nenhum, pois eu tinha tempo garantido e aposentei-me com meus vencimentos" ${ }^{\prime 30}$. No entanto, ele diz que não tinha vontade de se aposentar, pelo contrário, "tinha vontade de criar uma turma lá, de assistentes e alunos meus". Mas a aposentadoria não o isolou: "Continuam a vir a minha casa e ter esse contato. Desse contato com o pessoal, eu senti falta no começo" 31 .

Witter (1998, p. 22) relata um encontro com Sérgio Buarque de Holanda e alguns orientandos e assistentes seus, em sua casa na Rua Buri, quando, de certa maneira, pede licença para se aposentar:

Ele queria comunicar, em primeiro lugar, aos seus subordinados o seu desejo de fazer um protesto, através de sua aposentadoria, a ser solicitada durante a reunião do Departamento, firmando a sua posição de intransigente defesa da Universidade e convicta solidariedade aos professores cassados pelo regime militar.

Witter relata também que Sérgio não o faria se a sua decisão pudesse afetar um ou alguns de seus orientandos. Posteriormente, na reunião do Departamento de História, realizada no dia 23 de maio de 1969, Sérgio declara que seu pedido de aposentadoria "foi um gesto de protesto contra a aposentadoria forçada de numerosos professores". Assim, em 29 de abril, resolveu fazer o único gesto de protesto e,

(...) como não tem esperanças de que a situação mude no pouco tempo que Ihe resta na Universidade, o único gesto que Ihe resta é se ligar, pela aposentadoria, àqueles aposentados de modo forçado. Pediu que a justificação constasse de ata e disse que essa explicação era devida a todos e aos que votaram nele ${ }^{32}$.

Esse gesto, longe de ser egoísta, na medida em que "já tinha tempo para 
aposentadoria" e "nada perdia monetariamente", revela um protesto, mesmo que individual, contra toda sorte (seria azar?) por que passava a universidade naqueles anos. Certa vez, Sérgio Buarque de Holanda disse que gostava do clima da FFCL, que ficava na Rua Maria Antonia, 294, pois era possível encontrar todo mundo em seus corredores, possibilitando, dessa forma, o contato direto e certa socialização que Ihe agradara muito.

A FFCL ficou na Maria Antonia até 3 de outubro de 1968, data da fatídica "Guerra da Maria Antonia", episódio marcado pelo conflito entre os estudantes da USP e da Universidade Mackenzie, que deixou como saldo (negativo) a total destruição da Faculdade de Filosofia. Em um texto bem interessante sobre esse episódio, Irene Cardoso (2001) revê as fontes primárias desse acontecimento, realizando uma análise do Livro branco dos acontecimentos da Maria Antonia (2 e 3 de outubro de $1968^{33}$ ). Para a autora, esses acontecimentos tiveram muitas causas, entre as quais o conflito existente entre estudantes considerados comunistas e o aumento da repressão por parte do regime militar. A depredação do patrimônio público foi ignorada por parte das autoridades responsáveis, entre as quais a própria reitoria e o Secretário de Segurança Pública. Cardoso defende a tese de que existia, sim, um interesse por parte do regime militar e de seus defensores em destruir a FFCL e esse processo começava pela destruição física ${ }^{34}$.

Com isso, a FFCL foi obrigada a se instalar na Cidade Universitária às pressas, em lugar ainda sem estrutura e relativamente deserta, sem condições mínimas de cumprir o papel de produção do conhecimento. Segundo Cardoso (2001, p. 109),

Para além de uma dimensão estritamente política, as aposentadorias compulsórias de professores que logo se seguiram, em abril de 1969, significaram a quase inviabilização de alguns cursos da Faculdade de Filosofia, ao mesmo tempo em que caracterizavam a destruição de um patrimônio cultural acumulado por vários anos, que não pôde ser retomado mais, na mesma orientação. Um clima de intimidação, em alguns momentos de terrorismo mesmo, marcou os anos que se seguiram à mudança para a Cidade Universitária: cercos e invasões policiais; buscas e prisões de professores e estudantes; presença de policiais informantes em salas de aula e até mesmo de um dos torturadores da OBAN matriculado num de seus cursos; buscas e revistas em salas de professores à noite.

A "solução final" veio com a Reforma Universitária (Lei 5.540/68), que estabeleceu a dissolução da figura institucional da Faculdade de Filosofia, Ciências e Letras, desmembrada em vários Institutos e Faculdades (nove no total). Iniciavase, assim, o processo de "mercantilização" do saber e sua transformação tecnicista, além da adaptação da universidade nos moldes capitalistas de produção
33. Segundo Irene Cardoso (2001), a comissão responsável pela elaboração desse documento foi presidida pelo professor Simão Mathias e, como relator, o professor Antonio Candido. Este último guardou a única cópia existente desse documento.

34. Sobre o processo de perseguição e aposentadoria de alguns professores, ver: ADUSP. O livro negro da USP: o controle ideológico da universidade. São Paulo: Brasiliense, 1979. 
35. Folhetim, 2606-1977 (Siarq/Unicamp).

36. Siarq/Unicamp. e resultados.

Com certeza, todo esse processo levou Sérgio Buarque de Holanda a abreviar sua trajetória na USP. Seu gesto, mais do que de protesto, foi, mais uma vez, coerente com sua visão de mundo: democrática e crente de que a universidade deve cumprir o papel de propagadora dos valores elementares, tais como a liberdade e a democracia. Neste caso, seu silêncio, diz muito mais do que qualquer coisa.

\section{A vida fora da universidade}

"A universidade em São Paulo está dizimada. Uma desagregação que começou e não pode parar" ${ }^{\prime 3}$, bracejava Sérgio Buarque de Holanda quase no final de sua vida. Em carta recebida do Grupo Abril, datada de 27 de maio de 196936, dizia que,

(...) nos dias de hoje, entretanto, os melhores valores de nossa intelectualidade estão sendo afastados por razões espúrias enquanto mestres como o Senhor são obrigados pela dignidade a aposentar-se, oferecendo solidariedade aos atingidos. Acabarão restando os medíocres, os manietados e os indecisos.

Mas a ausência do contato direto na universidade não levou o historiador a viver de forma pacata a sua aposentadoria. Com mais tempo livre, pôde dedicar-se a outros projetos e escrever outros livros que já havia esboçado, além de fazer algumas viagens. Em 1973, foi à Europa, visitando a Itália, a Grécia, a Turquia, a Hungria, a Áustria, parte da Alemanha, a Holanda, a Inglaterra e a França. Em 1974, a convite do governo venezuelano, foi a Caracas para a instalação da Biblioteca Ayacucho. Em 1974, participou da reunião de escritores latino-americanos em Caracas, Venezuela. Em 1976, foi à Europa, visitando a Itália, a Tcheco Eslováquia, Berlim e Paris, ali pesquisando e trazendo material do Quai d’Orsay.

Entre as muitas homenagens que recebeu em vida, uma das mais importantes foi na Universidade de Oxford, que criou a cadeira Sérgio Buarque de Holanda em convênio com a Universidade de Campinas.

Em 1979, colabora em volume de homenagem a Antonio Candido, "Esboço de Figura". Foi uma das últimas produções de cunho deferencial.

\section{Conclusão}

Acreditamos que analisar a trajetória intelectual de Sérgio Buarque de Holanda nos leve a repensar o próprio papel do intelectual na sociedade moderna. 
É claro que o momento histórico é muito diferente do que aquele da década de 50 , onde a universidade pulsava democracia e atingíamos a maturidade em diversos campos do saber. Sérgio Buarque de Holanda contribuiu não só para a consolidação da historiografia brasileira, mas, devido à sua atuação no IEB, lançou as bases para a compreensão mais ampla do processo histórico, calcado na interdisciplinaridade e no abandono definitivo de qualquer método rígido ou preconceito acadêmico, já que ele primava pela liberdade total das ciências de suas amarras, o que levou alguns historiadores a uma compreensão muitas vezes equivocada da realidade histórica.

A Universidade de São Paulo, ao convidar Sérgio Buarque de Holanda para seus quadros, entendia que era preciso encontrar uma maneira de angariar os meIhores quadros que tínhamos à época para poderem contribuir com a produção e a difusão do conhecimento. $O$ intelectual independente que foi Sérgio Buarque de Holanda quase não pôde ingressar na universidade pública, devido às exigências de titulação e à experiência profissional, coisas com que ele nunca se preocupou. Uma vez dentro da universidade, pôde desenvolver a pesquisa científica e reestruturar todo o curso de História, dando uma dimensão muito mais apropriada às necessidades do País e às exigências do mercado. É importante ressaltar que Sérgio Buarque de Holanda pensava nisso numa época em que a pesquisa científica, de forma sistematizada, ainda engatinhava no Brasil.

A idealização e a criação do IEB foi outra grande contribuição do historiador na USP. Ele percebeu que, para compreendermos os fatos históricos e os problemas sociais brasileiros, era necessário a contribuição interdisciplinar, pois, assim, poderíamos ter uma percepção melhor do todo. Mais uma vez o historiador esteve à frente de seu tempo, pois a questão da interdisciplinaridade, ou em termos atuais os "temas transversais", que são a base de todo os Parâmetros Curriculares Nacionais (PCNs), demonstram que o conhecimento não deve ser fragmentado.

Abstract: The main purpose of the article is to describe and to analyse Sérgio Buarque de Holanda's trajectory in Universidade de São Paulo (USP). At USP, he could dedicate himself entirely in what he liked to do: to research. There, Sérgio Buarque de Holanda formed a researchers' group and he changed the teaching routes in History course, which formed only Elementary and High School teachers. He idealized and founded the "Instituto de Estudos Brasileiros" (Brazilian Studies Intitute), a multi-disciplinary institution responsible for important researches included the theme "Brasil". In this Institute (IEB), he formed a ample archive and a important library. In 1969, the 13-years-job at USP finished itself in a careworm process, when he asked for his retirement in sympathy with other retired professors compulsorily by Al-5.

Keywords: Sérgio Buarque de Holanda, Universidade de São Paulo, Intelectual independence. 
Referências Bibliográficas

Caldeira, João Ricardo Castro (org.) (2005) Perfis Buarqueanos - ensaios sobre Sérgio Buarque de Holanda. São Paulo, Fundação Memorial da América Latina/ IMESP.

Caldeira, João Ricardo Castro (2000) IEB: origem e significado - um estudo sobre o Instituto de Estudos Brasileiros da Universidade de São Paulo. São Paulo, Tese (Doutorado), Faculdade de Filosofia Letras e Ciências Humanda da Universidade de São Paulo.

Candido, Antonio (1992) "Inéditos sobre Literatura Colonial" in COLÓQUIO DA UERJ, Rio de Janeiro: Imago.

Cardoso, Irene (1982) A universidade da comunhão paulista. São Paulo, Cortez. (2001) Para uma crítica do presente. São Paulo: Editora 34.

Dias, Maria Odila Leite Silva (1994) "Sérgio Buarque de Holanda na USP". Estudos Avançados, São Paulo, vol. 22, n. 8, set/dez.

Graham, Richard (1987) "Uma entrevista". Revista do Brasil, Rio de Janeiro, vol. 6, n. 3.

Holanda, S. B. (2004) "Corpo e alma do Brasil - entrevista de Sérgio Buarque de Holanda". Novos Estudos CEBRAP, São Paulo, n. 69: 03-14.

vol. 6, n. 3 .

(1987a) "Corpo e alma do Brasil". Revista do Brasil, Rio de Janeiro,

Linhares, Maria Y. (1987) "O paraíso, buscando um dia, nestas terras". Revista do Brasil, Rio de Janeiro, vol. 6, n. 3.

Oliveira, Fátima Bayma (1995) Pós-Graduação - educação e mercado de trabaIho, Campinas: Papirus.

Miceli, Sérgio (1979) Intelectuais e a classe dirigente no Brasil, São Paulo: Difel.

Pécaut, Daniel (1990) Os intelectuais e a política no Brasil, São Paulo: Ática.

Ridenti, M. (2003).

Queiroz, Suely Robles (2005) "Sérgio Buarque, meu mestre" in João Ricardo de Castro Caldeira (org.) Perfis Buarqueanos: ensaios sobre Sérgio Buarque de Holanda. São Paulo, Fundação Memorial da América Latina/ IMESP.

Witter, José Sebastião (2002) "Sérgio Buarque de Holanda 1902-2002". Notícia Bibliográfica e Histórica, Campinas, n. 187: 297-306, out-dez. 
Witter, José Sebastião (2002) "Sérgio Buarque de Holanda, catedátrico por excelência”. Ethnos, São Paulo, vol. 2, n. 1: 9-16, set.

(1998a), "Sérgio Buarque de Holanda - algumas lembranças". Revista USP - Dossiê Intérpretes do Brasil - anos 30, São Paulo, n. 38: 20-27, jun/ jul/ago.

(1988b), "Sérgio Buarque de Holanda, o professor" in Sérgio Buarque de Holanda vida e obra. São Paulo, Secretaria de Estado da Cultura/IEB-USP. 